\title{
Fault location identification of double circuit transmission line using discrete wavelet transform
}

\author{
Abdul Hadi Bin Mustapha1, R. Hamdan², F. H. Mohd Noh ${ }^{3}$, N. A. Zambri ${ }^{4}$, M. H. A. Jalil ${ }^{5}$, \\ Marlia Morsin', M.F. Basar ${ }^{7}$ \\ ${ }^{1,2,5,6} \mathrm{Faculty}$ of Electrical \& Electronic Engineering, Universiti Tun Hussein Onn Malaysia, Malaysia \\ ${ }^{3,4}$ Faculty of Engineering Technology, Universiti Tun Hussein Onn Malaysia, Malaysia \\ ${ }^{7}$ Faculty of Engineering Technology, Technology Campus, Universiti Teknikal Malaysia Melaka, Malaysia
}

\begin{abstract}
Article Info
Article history:

Received Dec 1, 2018

Revised Mar 16, 2019

Accepted Apr 25, 2019

\section{Keywords:}

Discrete wavelet transform

Double circuit

Fast fourier transform

Fault location identification

ABSTRACT

The importance of supplying undisturbed electricity keep increasing due to modernization and lifestyle. Any disturbance in the power system may lead to discontinuation and degradation in the power quality. Therefore, detecting fault, fault type and fault location is a major issue in power transmission system in order to ensure reliable power delivery system. This paper will compare two prominent methods to estimate the fault location of double circuit transmission line. Those methods are Discrete Wavelet Transform algorithm and Fast Fourier Transform algorithm. Simulations has been carried out in MATLAB/Simulink and a variety of fault has been imposed in order to analyse the capability and accuracy of the fault location detection algorithm. Results obtained portrayed that both algorithms provide good performance in estimating the fault location. However, the maximum percentage error produced by the Discrete Wavelet Transform is only $0.25 \%$, $0.6 \%$ lower than maximum error produces by Fast Fourier Transform algorithm. As a conclusion, Discrete Wavelet Transform possesses better capability to estimate fault location as compared to Fast Fourier Transform algorithm.
\end{abstract}

Copyright () 2019 Institute of Advanced Engineering and Science. All rights reserved.

\section{Corresponding Author:}

Rohaiza Hamdan,

Department of Elecal Power Engineering,

Faculty of Electrical and Electronic Engineering,

Universiti Tun Hussein Onn Malaysia,

86400 Parit Raja, Johor, Malaysia.

Email: rohaiza@uthm.edu.my

\section{INTRODUCTION}

Transmission line is one of the main components in electrical power system which works as medium for transmitting electrical power generated to the consumers. In order to ensure a continuous electricity supply at the consumer side, maintenance and protection should be in high concern. However, most of the time, fault occur without a warning and can be at any place due to weather condition, failure of the equipment, error by human mistakes and others. The past two decades has viewed the rapid development in techniques for detection, classification and location of faults in power systems. The advancement in communication system, signal processing techniques, global positioning system (GPS), artificial intelligence system and machine learning have enabled more thorough research to be carried out in fault protection techniques. In the past, the locations of fault are hardly to determine due to limitation of technology and method in detecting and locating it in the real time monitoring. A key point for a fault location was an accuracy and reliability for the algorithm proposed. Fault location methods can generally be classified into two fundamental categories: techniques based on power-frequency components, and the other utilizing the higher-frequency components of the transient fault signals [1]. 
Theoretically, the frequency features of voltage and current will change dramatically whenever a fault occurs. If these features able to be identified and interpreted correctly, it may help protect the affected power system network to a great extent. It is also essential to classify the faults and identify which phases are involved. Various methods have been proposed to detect, classify, or locate faults in power transmission lines in recent years. One of it is Fourier Transform (FT). FT is a widely used mathematical tool which mainly used to analyse the frequency spectrum of a signal. Discrete FT (DFT) is applied when the signal is in discrete form. Authors in [2] used half cycle DFT to filter out the harmonic component in the signals and estimate its phasor element. [3-5] also adopted half cycle DFT to calculate fundamental and harmonic phasors of the signal to classify the fault-type in the studied system. WT is one of the most popular feature extraction methods for various fault diagnosis systems. In practice, most of the studies use Discrete Wavelet Transform to decompose the original current and voltage signals into its time and frequency spectrum. The WT decomposes signals over dilated and translated wavelet, which these compositions known as multiresolution analysis (MRA). In this approach, the high-frequency components of the signal will have a larger time resolution while its low-frequency components will have larger frequency resolution [6]. Wavelets have shown to perform better with non-periodic signals that contain short duration impulse components as is typical in power system transients [7].

A study on WT locating a fault has been done by many researches due to the strongest tool to analyse the fault because of its perfect time frequency localization ability [8-12]. WT has an advantages in detecting fault in transmission line where the WT provided a varies size analysis window in proportion to the frequency analysis hence offer a better compromise in terms of localization [13]. A research on FFT to locating fault by [14] state that the frequency of the first harmonic is utilized for determination of the fault location using travelling wave theory and the results show that the accuracy of the method is not affected by the fault resistance and phase angle of fault instant.

In [16], a classification algorithm of different faults on transmission line using fuzzy logic has been presented. FFT was applied in the study to determine the fundamental component of the current signals. Reference [18] has compared the performance of FT method with wavelet in detection and classification of faults on transmission line. But then, it is reported that wavelet give a significant performance for fault with more than single phase involved. Moreover, most fault studied in the paper are single phase to ground faults. While in [17], a neural network based fault identification and classification scheme is proposed. Reference [19] also discussed the application of neural network in double end fed transmission line for faulty phase selection and fault distance location. Authors in [20] has proposed to classify only ground faults on double circuit transmission line using artificial neural network. Application of wavelet in simultaneous fault in transmission system identification is discussed in [15]. However, authors have suggested to improve the proposed algorithm in order to achieve the desired accuracy.

With the evolvement of wavelet, some researchers proposed to use new type of wavelet to obtained useful information from the voltage and current signals for fault identification and classification. In [21] and [22], the entropy (energy) of the signal was extracted using Discrete Wavelet Transform and fed to artificial neural network (ANN) for fault classification. In [23], the current and voltage signals at relay location is used and transformed into series of details and coefficient using Discrete Wavelet Transform. These details and coefficient are then fed to ANN for fault detection and classification

The work presented in this paper deals with fault location detection using Discrete Wavelet Transform for three types of faults in double-circuit transmission lines. A $220 \mathrm{kV}$ line double end fed $200 \mathrm{~km}$ in length double circuit transmission line has been chosen as the studied system. The work reports the result of an extensive 'offline' studies using Matlab and its associated toolboxes: Simulink, SymPowerSystems and Wavelet toolbox. All the three types of faults (single-line to ground fault, line-to-line fault and dounle-line to ground fault) has been assigned on both lines in double-circuit transmission line at the same time. The aptness and the effectiveness of the selected technique is analysed and compared with the percentage error of the fault location using Fast Fourier Transform.

\section{DISCRETE WAVELET TRANSFORM FAULT DETECTION AND FAULT LOCATION ALGORITHM}

Figure 1 below provides the algorithm of implementing Discrete Wavelet Transform which has been proposed in [24], in order to detect the fault occurrence on double circuit transmission line. In detecting the fault on transmission line, three phase current signal will be recorded, and any inception of fault will change the amplitude of the three-phase current signal will be extracted to the wavelet decomposition. Figure 2 depict the wavelet decomposition process. 


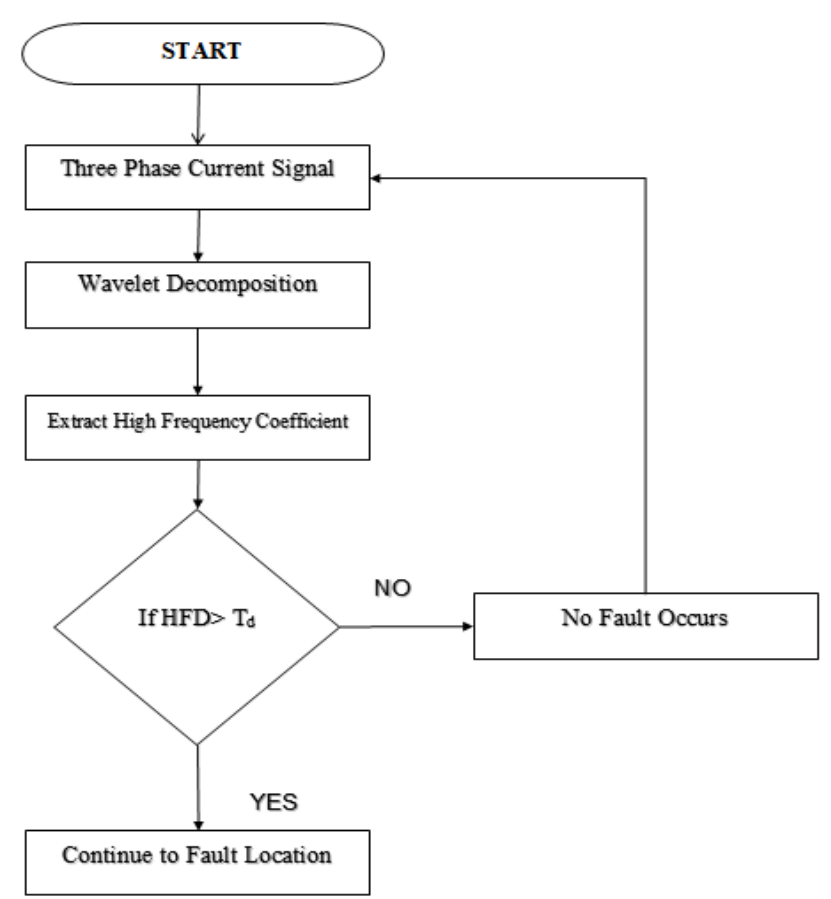

Figure 1. An algorithm in detecting fault using discrete wavelet transform

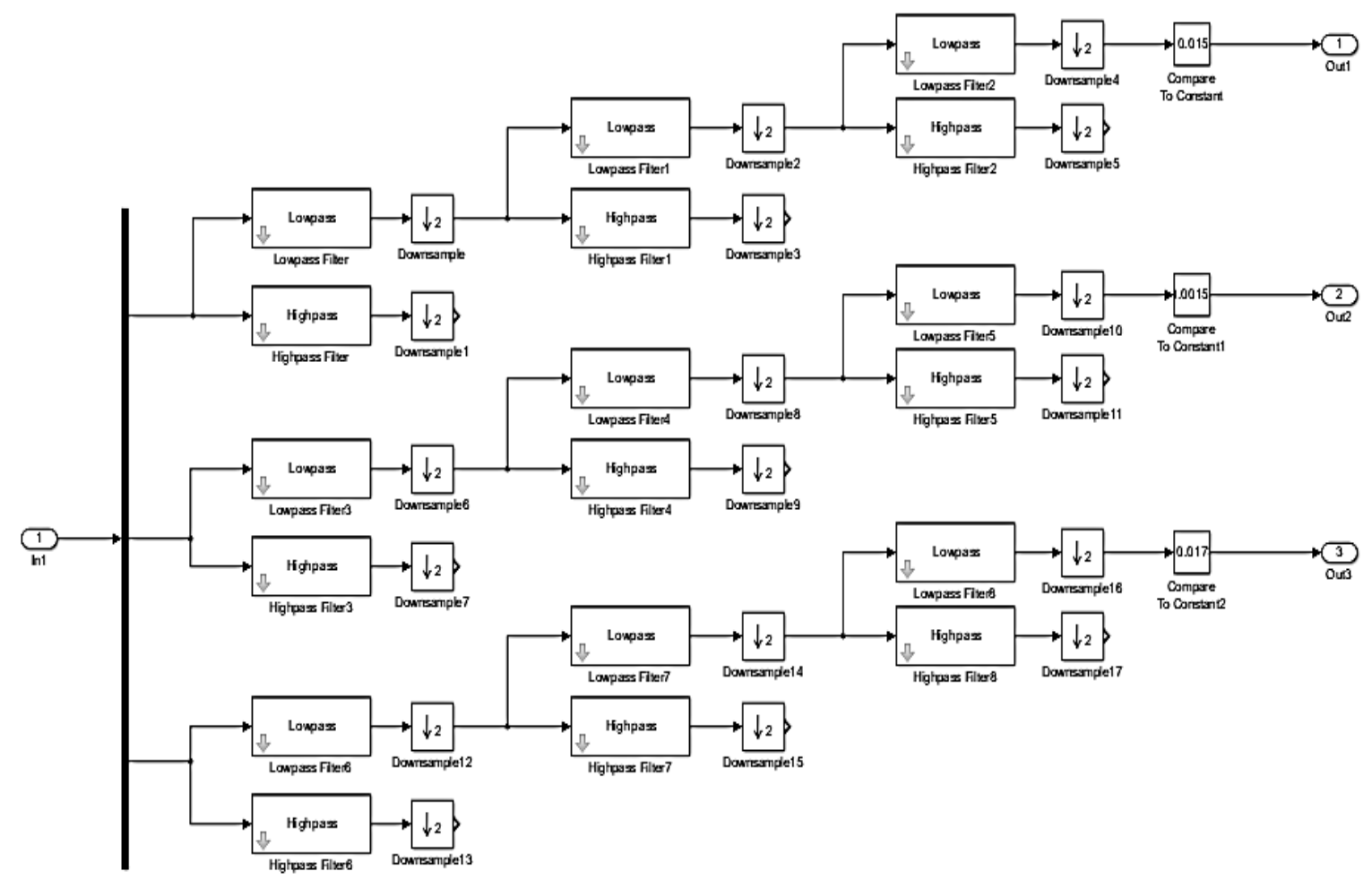

Figure 2. Wavelet decomposition process

Wavelet decomposition gains an input from the current measurement in bus terminal. The signal then, started to decompose into three levels of decomposition by passing through a low pass filter. The result from the decomposition using discrete wavelet decomposition filter will determine the fault inception by 
obtaining the high frequency detail. If the resulted absolute value from the first difference of high frequency detail coefficient is greater than the threshold value, it denotes that fault is established within the transmission lines. Once fault detected, the location of the fault will be determined further using:

$$
\text { Fault Location: } \frac{F L_{R T} X T_{L}}{F L_{R T} X F L_{S T}}
$$

Where FLST is a single faulted phase from the source terminal while FLRT depict local fault location information from the remote terminal and the length of transmission is represented as TL.

\section{FAST FOURIER TRANSFORM FAULT LOCATION ALGORITHM}

The proposed method [25] possess some advantages where fault resistance and in feed from both substations do not affect fault location estimation. Also, the different source impedance values will not influence the fault location estimation and the data is not required. During fault, the harmonic component was added in the voltage and current signal. Thus, an algorithm based on the harmonic component has been developed to locate the fault. The faulted voltage and current signal has to be extracted from the transmission line model before filtering out the harmonic component from the signal. Figure below shows a voltage and current signal extraction. Later, The FFT block functioned to convert the sampled voltage and current waveforms into magnitude and phase angle at every samples. Whilst, the low pass filter block functioned as filtering a harmonic component. Figure 3 provides the block diagram of fault location using Fast Fourier transform.

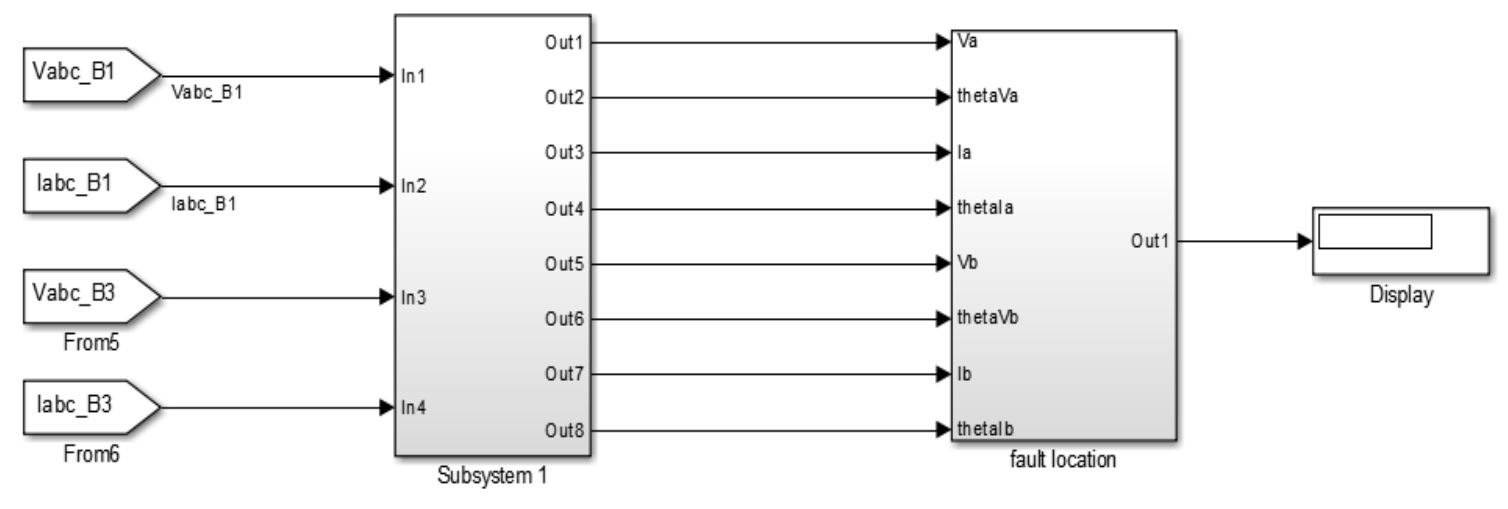

Figure 3. Fault location using Fast Fourier transform

The output from the FFT block was being converted into a magnitude and phase before the estimation of fault location. The fault location later can be estimated using equation given in [25], which can be summarized as:

$$
m=\frac{V a-V b+\frac{I b}{3}\left(Z_{1}+Z_{2}+Z_{0}\right)}{\frac{I a+I b}{3}\left(Z_{1}+Z_{2}+Z_{0}\right)}
$$

Where;

$\boldsymbol{m}=$ line length (in per unit)

$\mathbf{Z}_{\mathbf{1}}=$ Positive sequence impedance

$\mathbf{Z}_{\mathbf{2}}=$ Negative sequence impedance

$\mathbf{Z}_{\mathbf{0}}=$ Zero sequence impedance

$\mathbf{V}_{\mathbf{A}}=$ Phase to ground voltage seen from substation A

$\mathbf{V}_{\mathbf{B}}=$ Phase to ground voltage seen from substation B

$\mathbf{I}_{\mathbf{A}}=$ Phase current from substation A

$\mathbf{I}_{\mathbf{B}}=$ Phase current from substation B 


\section{DOUBLE LINE TRANSMISSION MODEL}

In order to investigate the applicability of the proposed method, a model of double line transmission system as shown in Figure 4 is considered for the purpose. The system testing model has been developed using MATLAB/Simulink Software. The model is composed by $220 \mathrm{kV}$ line with $200 \mathrm{~km}$ in length where single source and the short circuit capacity has been set to $1.25 \mathrm{GVA}$. Xs/Rs ratio of the source is set to 10 [26]. The parameters of the double line model used in this circuit are as listed in Table 1.

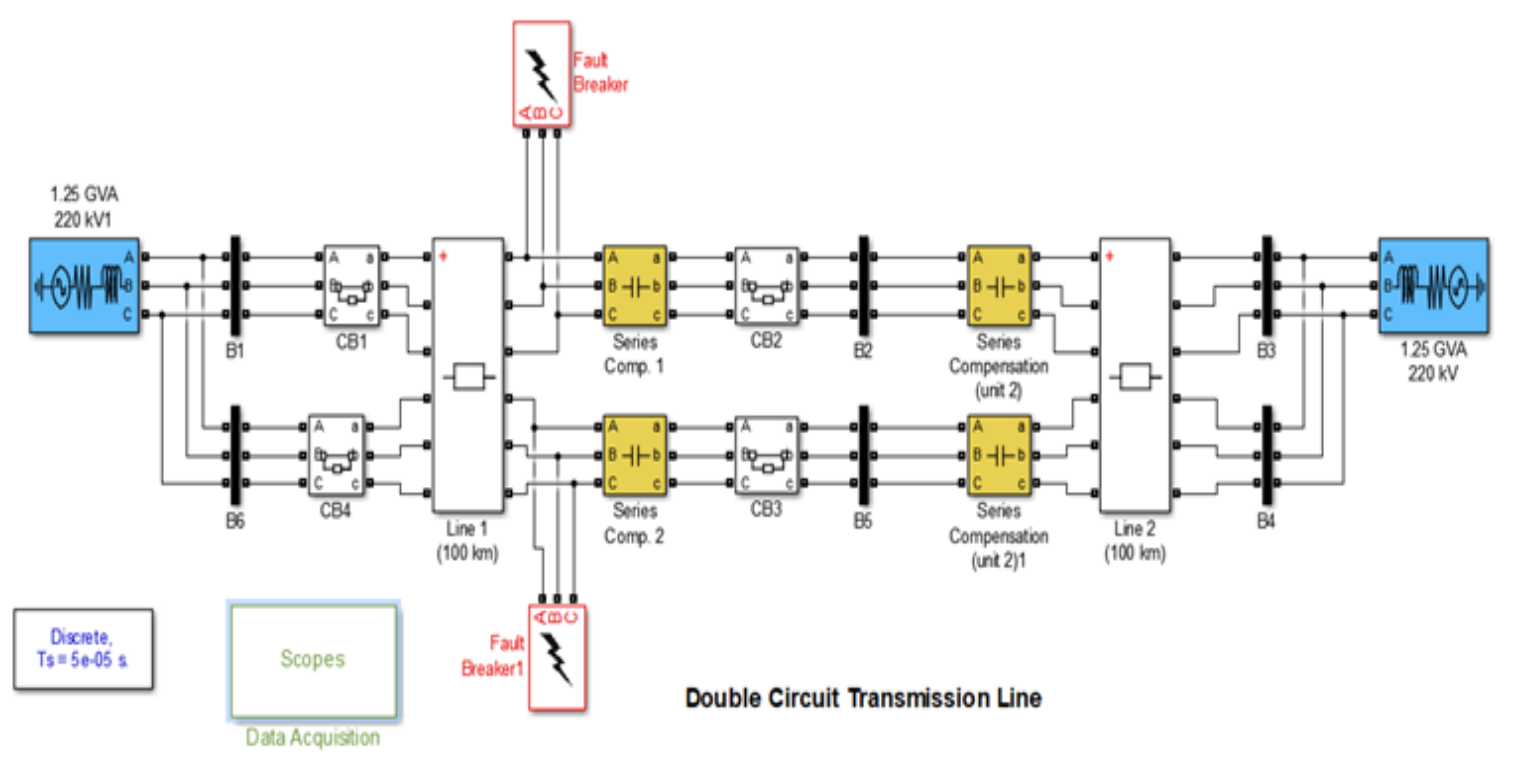

Figure 4. Effects of selecting different switching under dynamic condition

Table 1. Parameter used in the Double Line Transmission Model

\begin{tabular}{cc}
\hline Parameter & Value \\
\hline Positive sequence resistance, $\mathrm{R}_{1}$ & $0.01809 \Omega / \mathrm{km}$ \\
Zero sequence resistance, $\mathrm{R}_{0}$ & $0.2188 \Omega / \mathrm{km}$ \\
Zero sequence mutual resistance, $\mathrm{R}_{0 \mathrm{~m}}$ & $0.20052 \Omega / \mathrm{km}$ \\
Positive sequence inductance, $\mathrm{L}_{1}$ & $0.00092974 \mathrm{H} / \mathrm{km}$ \\
Zero sequence inductance, $\mathrm{L}_{0}$ & $0.0032829 \mathrm{H} / \mathrm{km}$ \\
Zero sequence mutual inductance, $\mathrm{L}_{0 \mathrm{~m}}$ & $0.0020802 \mathrm{H} / \mathrm{km}$ \\
Positive sequence capacitance, $\mathrm{C}_{1}$ & $1.2571 \mathrm{e}-008 \mathrm{~F} / \mathrm{km}$ \\
Zero sequence capacitance, $\mathrm{C}_{0}$ & $7.8555 \mathrm{e}-009 \mathrm{~F} / \mathrm{km}$ \\
Zero sequence mutual capacitance, $\mathrm{C}_{0 \mathrm{~m}}$ & $-2.0444 \mathrm{e}-009 \mathrm{~F} / \mathrm{km}$ \\
\hline
\end{tabular}

\section{RESULTS AND ANALYSIS}

\subsection{Fault Detection and Fault Location Estimation using Discrete Wavelet Transform}

Various types of faults including single line to ground fault, line to line fault and double line to ground fault, has been initiated into the system randomly along the transmission lines. Figures 5, 6 and 7 illustrates the wavelet decomposition of the current signal during faults. For all types of faults, the fault existence has been confirmed after the 3rd level decomposition process via d1 value in the decomposition equation. Table 2 tabulate the results for faults detection status from using Discrete Wavelet Transform algorithm.

Table 2. Discrete Wavelet Transform Fault Detection in Transmission Line

\begin{tabular}{cccc}
\hline Location fault $(\mathrm{km})$ & Single line to ground fault & Line to line fault & Double line to ground fault \\
\hline 40 & Fault detected & Fault detected & Fault detected \\
80 & Fault detected & Fault detected & Fault detected \\
120 & Fault detected & Fault detected & Fault detected \\
160 & Fault detected & Fault detected & Fault detected \\
\hline
\end{tabular}




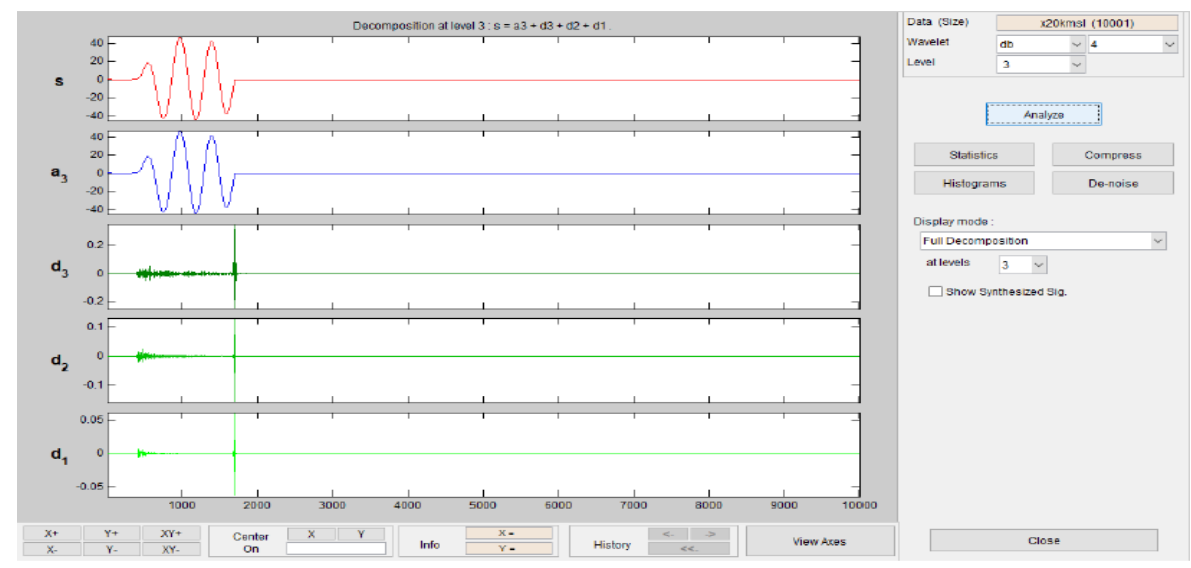

Figure 5. A wavelet decomposition of current signal during single line to ground fault

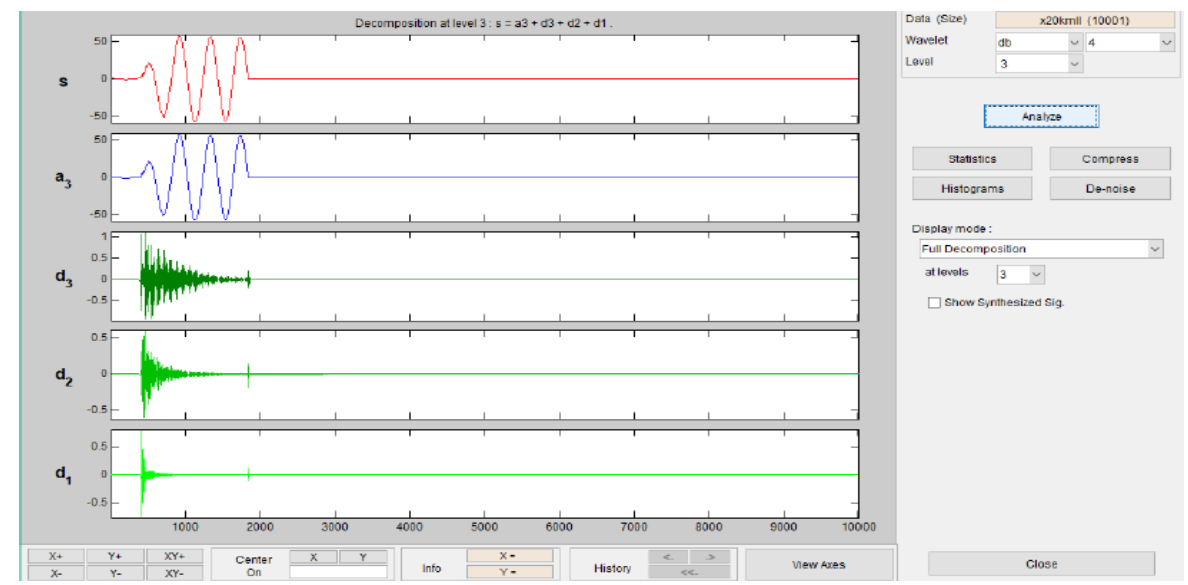

Figure 6. A wavelet decomposition of current signal during line to line fault

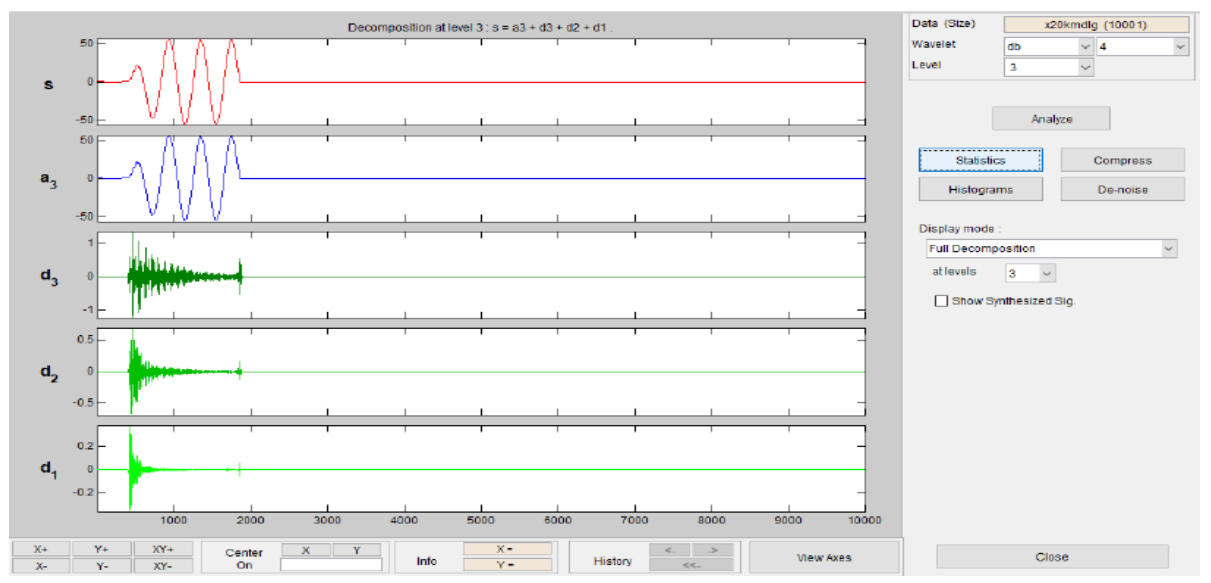

Figure 7. A wavelet decomposition of current signal during double line to ground fault

From the results, it can be concluded that Discrete Wavelet Transform has the ability in detecting fault within transmission line in any cases of fault and without concerning the location of the fault itself. Further, Table 3 list down the estimated faults location under various positions along the transmission line. Also, only single line to ground fault is being considered during the simulation. The highest error recorded is $0.5 \mathrm{~km}$ 
Table 3. Estimated Fault Location in Transmission Line using Discrete Wavelet Transform

\begin{tabular}{ccc}
\hline Actual fault location $(\mathrm{km})$ & Estimated fault location $(\mathrm{km})$ & Error $(\mathrm{km})$ \\
\hline 20 & 19.95 & 0.05 \\
40 & 39.90 & 0.10 \\
60 & 59.85 & 0.15 \\
80 & 79.80 & 0.20 \\
100 & 99.75 & 0.25 \\
120 & 119.70 & 0.30 \\
140 & 139.65 & 0.35 \\
160 & 159.60 & 0.40 \\
180 & 179.55 & 0.45 \\
200 & 199.50 & 0.50 \\
\hline
\end{tabular}

\subsection{Fault Location Estimation using Fast Fourier Transform}

Whilst taking red phase as reference and implying single line to ground fault towards the double line transmission system, Table 4 tabulated the resulted estimated faults location under various positions along the transmission line by using Fast Fourier Transform algorithm. Error obtains ranging from lowest at $0.1 \mathrm{~km}$ to the highest at $1.7 \mathrm{~km}$.

Table 4. Estimated Fault Location in Transmission Line using Fast Fourier Transform Algorithm

\begin{tabular}{ccc}
\hline Actual fault location $(\mathrm{km})$ & Estimated fault location $(\mathrm{km})$ & Error $(\mathrm{km})$ \\
\hline 20 & 21.2 & 1.2 \\
40 & 40.9 & 0.9 \\
60 & 60.7 & 0.7 \\
80 & 80.4 & 0.4 \\
100 & 100.2 & 0.2 \\
120 & 119.9 & 0.1 \\
140 & 139.5 & 0.5 \\
160 & 158.8 & 1.2 \\
180 & 178.5 & 1.5 \\
200 & 198.3 & 1.7 \\
\hline
\end{tabular}

\subsection{Fault Location Estimation Comparison}

Table 5 provide the comparison of estimated fault detection location for single line to ground fault between Fast Fourier Transform algorithm and Discrete Wavelet Transform algorithm. Figure 8 and Figure 9 provide the comparison between both methods in terms of its estimated fault location and percentage errors of estimated fault location. In estimating the fault location, the maximum magnitude of the percentage error recorded is $0.85 \%$, which is obtained from Fast Fourier Transform. But the magnitude of error produced by implementing Discrete Wavelet Transform algorithm is mainly lower compared to the one produces from Fast Fourier Transform algorithm. The highest percentage error obtained by Discrete Wavelet Transform is only $0.25 \%$ where actual fault location is set to $200 \mathrm{~km}$.

Table 5. Estimated Fault Location in Transmission Line using Fast Fourier Transform Algorithm and Discrete Wavelet Transform Algorithm

\begin{tabular}{ccccc}
\hline $\begin{array}{c}\text { Actual fault location } \\
(\mathrm{km})\end{array}$ & $\begin{array}{c}\text { Discrete Wavelet Transform } \\
\text { Estimated fault location } \\
(\mathrm{km})\end{array}$ & $\begin{array}{c}\text { Error }(\%) \\
\text { Estimated fault location } \\
(\mathrm{km})\end{array}$ & 21.2 & 0.60 \\
\hline 20 & 19.95 & -0.025 & 40.9 & 0.45 \\
40 & 39.90 & -0.050 & 60.7 & 0.35 \\
60 & 59.85 & -0.075 & 80.4 & 0.20 \\
80 & 79.80 & -0.100 & 100.2 & 0.10 \\
100 & 99.75 & -0.125 & 119.9 & -0.05 \\
120 & 119.70 & -0.150 & 139.5 & -0.25 \\
140 & 139.65 & -0.175 & 158.8 & -0.60 \\
160 & 159.60 & -0.200 & 178.5 & -0.75 \\
180 & 179.55 & -0.225 & 198.3 & -0.85 \\
200 & 199.50 & -0.250 & & \\
\hline
\end{tabular}




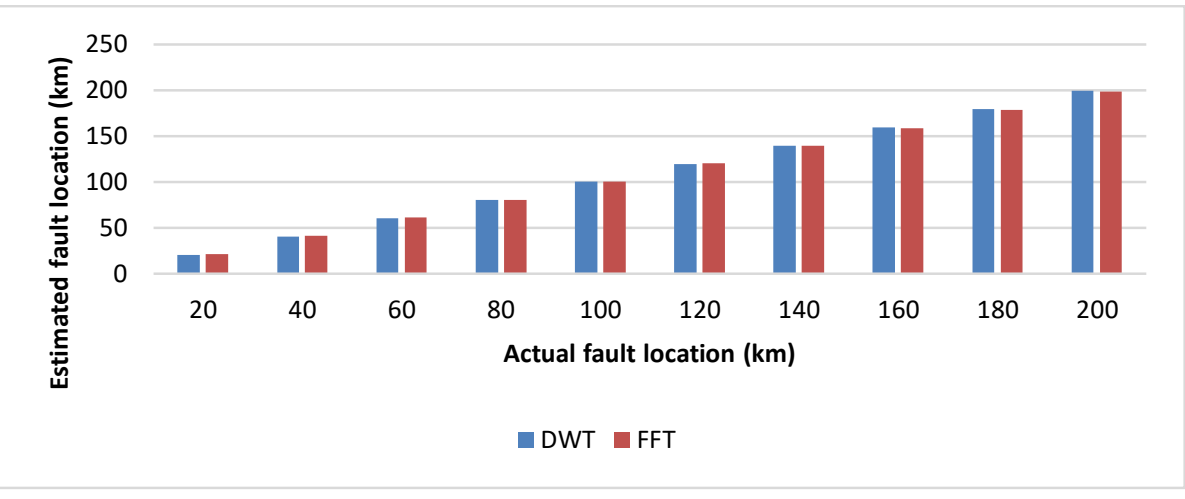

Figure 8. Estimated fault location in transmission line using Fast Fourier Transform algorithm and Discrete Wavelet Transform algorithm

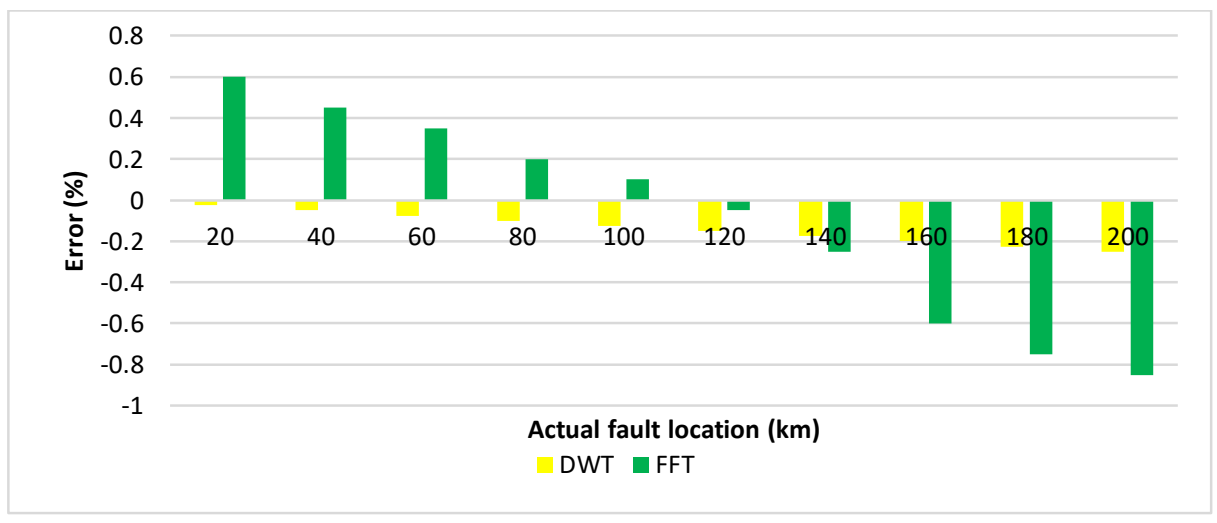

Figure 9. Error of estimated fault location in transmission line using Fast Fourier Transform algorithm and Discrete Wavelet Transform algorithm

\section{CONCLUSION}

The proposed method utilizes Discrete Wavelet Transform spectral energy values for fault location identification. Performance comparison of the studied method has been performed with Fast Fourier Transform. Both of the algorithms portray good performance of identifying fault location. However, results obtained indicate that the Discrete Wavelet Transform demonstrates higher accuracy capability as compared to Fast Fourier transform. In addition, Discrete Wavelet Transform algorithm also be able to detect the fault occurrences apart from estimating the faults location.

\section{ACKNOWLEDGEMENTS}

The authors would like to acknowledge the financial support received from the Research Management Centre (RMC) Universiti Tun Hussein Onn Malaysia (UTHM) under the Tier 1 Research Grant Scheme (Code H105).

\section{REFERENCES}

[1] J. Chang, "Single Ended Traveling Wave based Fault Location using Discrete Wavelet Transform," Master Thesis, University of Kentucky, 2014, pp. 1-79.

[2] Yu, S.-L., Gu, J.-C.: "Removal of Decaying DC in Current and Voltage Signals using A Modified Fourier Filter Algorithm”, IEEE Trans. Power Deliv., vol. 16, pp. 372-379, 2001.

[3] Das, B., Reddy, J.V.: "Fuzzy-Logic-based Fault Classification Scheme for Digital Distance Protection", IEEE Trans. Power Deliv., vol. 20, pp. 609-616, 2005.

[4] Jamehbozorg, A., Shahrtash, S.M.: "A Decision-Tree-based Method for Fault Classification in Single-Circuit Transmission Lines", IEEE Trans. Power Deliv., vol. 25, pp. 2190-2196, 2010.

[5] Jamehbozorg, A., Shahrtash, S.M.: "A Decision Tree-based Method for Fault Classification in Double-Circuit Transmission Lines”, IEEE Trans. Power Deliv., vol. 25, pp. 2184-2189, 2010.

Fault location identification of double circuit transmission line using discrete... (Abdul Hadi Bin Mustapha) 
[6] D Saxena, K Verma, and S Singh, "Power Quality Event Classification: An Overview and Key Issues", International Journal of Engineering, Science and Technology, 2.3, pp. 186-199, 2010.

[7] R Flores. _"Signal Processing Tools for Power Quality Event Classi_Cation", Lic. Eng_. PhD thesis. thesis, School Electrical Eng. Chalmers Univ., Göteborg, Sweden, Tech. Rep, 2003.

[8] K. Saravanababu, P. Balakrishnan, and D. K. Sathiyasekar, "Transmission Line Faults Detection, Classification, and Location using Discrete Wavelet Transform," Int. Conf. Power, Energy Control, pp. 233-238, 2013.

[9] Lou X, Loparo KA. "Bearing Fault Diagnosis based on Wavelet Transform and Fuzzy Inference", Mechanical systems and signal processing. vol. 18 (5), pp. 1077-95, 2004.

[10] Panigrahi BK, Ray PK, Rout PK, Mohanty A, Pal K., "Detection and Classification of Faults in A Microgrid using Wavelet Neural Network", Journal of Information and Optimization Sciences. Vol. 39(1), pp. 327-35, 2018.

[11] Silva S, Costa P, Gouvea M, Lacerda A, Alves F, Leite D., "High Impedance Fault Detection in Power Distribution Systems using Wavelet Transform and Evolving Neural Network", Electric Power Systems Research, vol. 154, pp. 474-83, 2018.

[12] Abdelgayed TS, Morsi WG, Sidhu TS, "A New Harmony Search Approach for Optimal Wavelets Applied to Fault Classification” IEEE Transactions on Smart Grid, vol. 9(2), pp. 521-9, 2018.

[13] P. Manivannan, P. C. Tapre, and C. Veeresh, "Accurate Fault Detection Technique for Power Transmission Line Using Wavelet Transform,” pp. 248 - 256, 2016.

[14] M. S. Mamis and M. Arkan, "FFT Based Fault Location Algorithm for Transmission Lines," 7th Int. Conf. Electr. Electron. Eng., pp. 71-75, 2011.

[15] Ngaopitakkal, W. Pongchaisrikul, A.Kundakorn, "Analysis of Characteristics of Simultaneous Faults in Electrical Power System using Wavelet Transform," in Proc. IEEE International Conf. on Sustainable Energy Technologies, pp.249-252, 2008.

[16] K.Razi, N.T.Hagh, G. Abrabian, "High Accurate Fault Classification of Power Transmission Line using Fuzzy Logic," Proc. of IEEE International Power Engg. Conf., pp. 42-46, 2007.

[17] H.Khorashadi-Zadeh,"Artificial Neural Network Approach to Fault Classification for Double Circuit Transmission Lines," in Proc. of IEEE Transmission and Distribution Conf., pp. 859-862, 2004.

[18] D.Das N.K.Singh, A.K.Sinha, "A Comparison of Fourier Transform and Wavelet Transform Methods for Detection and Classification of Faults on Transmission Lines", in Proc. of IEEE Power India Conf., 2006.

[19] A.Jain, V.S.Kale, A.S.Thoke, "Application of Artificial Neural Network to Transmission Line Faulty Phase Selection and Fault Distance Location," Proc. of IASTED International Energy and Power System Conf., 2006, pp. 262-267.

[20] A.Jain, A.S.Thoke, R.N.Patel, "Fault Classification of Double Circuit Transmission Line using Artificial Neural Network," International Journal of Electrical Systems Science and Engineering, vol.1, No. 4, pp.230-235, 2008.

[21] K. M. Silva, B. A. Souza, and N. S. D. Brito, "Fault Detection and Classification in Transmission Lines-based on Wavelet Transform and Ann," IEEE Trans. Power Del., vol. 21, no. 4, pp. 2058-2063, Oct. 2006.

[22] P. L. L. Mao and R. K. Aggarwal, "A Novel Approach to the Classification of the Transient Phenomena in Power Transformers using Combinedwavelet Transform and Neural Network," IEEE Trans. Power Del., vol. 16, no. 4, pp. 654-660, Oct. 2001.

[23] F. Martin and J. A. Aguado, "Wavelet-based ANN Approach for Transmission Line Protection," IEEE Trans. Power Del., vol. 18, no. 4, pp. 1572-1574, Oct. 2003.

[24] K. Kasinathan, "Power System Fault Detection and Classification by Wavelet Transforms and Adaptive Resonance Theory Neural," 2007.

[25] M. H. Idris, M. W. Mustafa, and Y. Yatim, "Effective Two-Terminal Single Line to Ground Fault Location Algorithm,” 2012 IEEE Int. Power Eng. Optim. Conf. PEOCO 2012 - Conf. Proc., no. June, pp. 246-251, 2012.

[26] J. Gracia, A. J. Mazón, and I. Zamora, "Best ANN Structures for Fault Location in Single- and Double-Circuit Transmission Lines, ” IEEE Trans. Power Deliv., vol. 20, no. 4, pp. 2389-2395, 2005.

\section{BIOGRAPHIES OF AUTHORS}

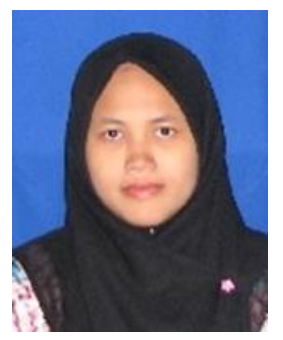

Rohaiza Hamdan is a lecturer in Department of Electrical Power Engineering, Faculty of Electrical and Electronic Engineering (FKEE), UTHM since 2003. She got her first degree in Electrical Power Engineering from Universiti Tenaga Nasional (UNITEN) on 2003. Three years later, she is granted with MSc. Electrical Power Engineering from Universiti Teknologi Malaysia, UTM. Her research interest evolved between power system stability, renewable energy and advance control applications. 

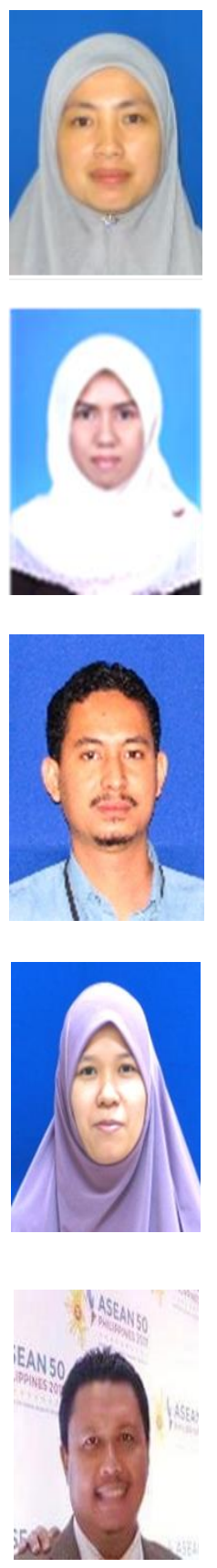

Faridah Hanim Mohd Noh received her B.Eng. degree in Electrical Power Engineering from Universiti Malaya (UM) in 2004, M.Eng. in Electrical Engineering from Universiti Tun Hussien Onn Malaysia (UTHM) in 2008 and Ph.D. degree in Computer Science and Electrical Engineering from Kumamoto University, Japan in 2016. She joined University Tun Hussien Onn Malaysia (UTHM), Malaysia in 2005. Since 2017, she has been with Faculty of Engineering Technology UTHM, and she is currently a senior lecturer. Her main areas of research interest are power quality, advanced digital signal processing and renewable energy.

Nor Aira Zambri received her BSc from Universiti Kebangsaan Malaysia in 2007 and MEng from Universiti Teknologi Malaysia in 2010, respectively. She received her $\mathrm{PhD}$ on electrical power engineering from Universiti Kebangsaan Malaysia in 2015. Currently, she works as senior lecturer in Universiti Tun Hussein Onn Malaysia and she can be reached at aira@uthm.edu.my.

Mohd Hafiz A. Jalil is a lecturer in Department of Mechatronic and Robotic Engineering, Faculty of Electrical and Electronic Engineering (FKEE), UTHM since 2003. He got her first degree in Electrical Engineering from Universiti Teknologi Mara (UiTM) on 2003. Three years later, he is granted with MSc. Electrical Engineering from Universiti Teknologi Malaysia, UTM. His research interest are on the application and development of advanced control and system identification.

Marlia Morsin received her B.Eng. degree in computer engineering from Universiti Technologi Malaysia (UTM) in 2002, the M.Eng. in electrical engineering from Universiti Tun Hussien Onn Malaysia (UTHM) in 2004 and the Ph.D. degree in microengineering and nanoelectronics from Universiti Kebangsaan Malaysia (UKM) in 2014. She joined University Tun Hussien Onn Malaysia (UTHM), Malaysia in 2004. Since 2004, she has been with Faculty of Electrical and Engineering, UTHM where she is currently a senior lecturer. Her main areas of research interest are nanomaterial and plasmonic sensor. Dr. Marlia is a Principal Researcher at Microelectronics \& Nanotechnology - Shamsuddin Research Centre (MiNT-SRC), Institute of Integrated Engineering (I2E), Universiti Tun Hussein Onn Malaysia.

Mohd Farriz Basar obtained a B.Sc. in Electrical Engineering and a M.Sc. in Electrical Power Engineering from the Universiti Teknologi Malaysia in 2001 and 2009 respectively; and a Ph.D. in Renewable Energy from the Universiti Kebangsaan Malaysia, in 2017. He is a professional engineer with practising certificate registered under Board of Engineer Malaysia since 2013. He has been involved in the field of innovation and renewable energy for over fifteen years. His main contributions are in pico hydro generation system, humanistic innovation and applied industrial research. He has published over 50 research papers in journals and conferences, also he managed to produce 7 original books, book chapters and module. He often represents the country and university in international product exhibitions and innovation competitions. Through the inventions, he has won over than 130 special awards, medals of gold, silver and bronze from various competition inside and outside the country. Currently, he is the Deputy Dean (Research and Industry Network) for the Faculty of Electrical and Electronic Engineering Technology (FTKEE), Universiti Teknikal Malaysia Melaka. 